\title{
The Utility of Video Diaries for Organizational Research
}

Mike Zundel $^{1}$

Robert MacIntosh ${ }^{2}$

David Mackay $^{1}$

1. University of Liverpool, School of Management, Liverpool, UK

2. Heriot-Watt University, School of Management and Languages, Edinburgh, UK

Accepted for publication in Organizational Research Methods published by SAGE. 


\section{Abstract}

This paper assesses the utility of video diaries as a method for organization studies. While it is frequently suggested that video-based research methodologies have the capacity to capture new data bout the minutiae of complex organizational affairs, as well as offering new forms of dissemination to both academic and professional audiences, little is known about the specific benefits and drawbacks of video diaries. We compare video diaries with two established and 'adjacent' methods: traditional diary studies (written or audio) and other video methods. We evaluate each in relation to three key research areas: bodily expressions, identity, and practice studies. Our assessment of video diaries suggests that the approach is best used as a complement to other forms of research and is particularly suited to capturing plurivocal, asynchronous accounts of organizational phenomena. We use illustrations from an empirical research project to illustrate our claims video diaries before concluding with five points of advice for researchers wishing to employ this method.

Keywords: Video Diaries, Video Methods, Diary Studies, Organizational Research 


\section{Introduction}

Video cameras are now routinely embedded in smartphones and computers, creating new possibilities for researchers to gather data recorded on devices used by participants in the conduct of their organizational lives. In this paper we evaluate one variant of such technology-based research: self-directed video diaries. It is frequently suggested that video-based methodologies have the capacity to capture the minutiae of complex organizational affairs by accessing new types of data as well as offering new forms of dissemination to both academic and professional audiences (e.g. Knoblauch \& Schnettler, 2006: 335; Iedema et al., 2006). Yet little is known about the additional organizational data video diaries may capture; the specific benefits and drawbacks of video and their suitability for specific organizational phenomena and research approaches; and what practical aspects require consideration.

We evaluate the additive contribution of video diaries by contrasting them with 'adjacent' methods: other forms of diary studies (written or audio) and other, non-diary, video methods. We assess each method in relation to three themes: bodily expressions such as the gestures employed to enjoin others in one's sensemaking processes (Clarke, 2011); identity, self-perception and the processes of identity formation, change, fragmentation or framing (Brown, 2014); and finally organizational practice, either in the form of individual actions exhibited as part of organizational work, or in terms of the orchestration of work patterns between individuals in everyday organizational life (Smets et al., 2014).

These three themes place differing demands on research methods by specifying, inter alia, the purposive frame of analysis; relevant units of analysis and levels of abstraction; as well as the acknowledged role and influence of the researcher. We draw on published research using diary and other video approaches and contribute 
excerpts from an empirical study in which we employed video diaries. We suggest that video diaries provide an efficient and effective means of gathering large amounts of dispersed and asynchronous data from difficult to access organizational areas. Video diaries can provide both: more and richer data. When studying bodily expressions, video diaries can produce close-up recordings of sometimes intense moments of joy or despair, confessions and worries, as well as conflicts and alliances. For identity researchers, video dairies allow access to multiple actors as they reflect on the roles they inhabit, providing details of identity developments and struggles over time. For students of practices, video diaries can add participants' intense reflections on organizational affairs, access to dispersed communities of practice and, as 'unselective' recording devices, they offer audio-visual glimpses into the wider work-world of the participants.

These benefits are offset by a lack of in-situ work recordings; the relative lack of control of the researcher when it comes to content and recording settings; and potentially challenging ethical issues. We also reflect upon our own experiences with video diaries in terms of the ease with which they allow the creation of seemingly coherent flows of audio-visual materials, veiling the geographical and temporal distances in actual organizational settings in which they were recorded; and the influence of processes of manipulation of video diary clips and how these translate, rather than transmit organizational phenomena. As such they sometimes make uneasy viewing for researchers. We conclude by suggesting that video diaries may be at their most effective when combined with more traditional research methods and by elaborating practical considerations for researchers wishing to use video diaries. 


\section{Case study background}

The video diary extracts presented in this paper formed part of a wider study of distributed sense-making processes in relation to strategic decisions within an entrepreneurial engineering service firm. We gathered data in a series of traditional interviews as well as facilitating strategy workshops within the firm. The strategy workshops and interviews established working relationships with the management team and facilitated the negotiation of 'access' for the video diary study. Managers from the firm were invited to upload a video diary at least weekly using a private 'YouTube' channel where the researchers could see entries from all of the diarists but each participant could only access their own recordings. We received 258 minutes of video recordings in 28 separate uploads from four diarists between July and September 2013. This period coincided with substantial change within the firm.

We offered instructions to the diarists in two ways. First, in form of instructions to "comment on any developments arising in the life of the organization since your last recording that you feel to be significant" (excerpt from invitation email to participants). Second, in approximately monthly cycles we transcribed the content of the diary entries and conducted a thematic analysis which acted as a guide to the next round of data collection. Each subsequent email instruction combined both the general prompt (“comment on any developments" and a more specific prompt from previous analysis, for instance, "comment on what you'd see as the next stage of the software development project"). Other disciplines have long-standing coding regimes for non-verbal behaviour (Ekman \& Friesen, 1969) and contemporary scholars use the ELAN system (Lausberg \& Sloejes, 2009) in much the same way that organizational researchers use NVivo or similar tools to manage complex textual, audio and visual data. We did not employ these approaches in our treatment of the data for this paper 
but did make note of audio and visual cues such as body language, facial expression, etc. Our analysis initially consisted of extended thematic coding of the transcribed text. We also repeatedly watched all recordings and then produced sequences combining shorter clips of scenes we found relevant and which are partly reproduced below.

\section{Video + diaries}

Video diaries are a relatively recent addition to the organizational researcher's toolkit even though their constituent parts - both videos and diaries - have relatively long traditions in social science research, dating back, at least, to the countless photographs and reels of film the anthropologists Margaret Mead and Gregory Bateson exposed in Bali in the 1930s (see Harries-Jones, 1995; Erickson, 2011). In organizational research, video recordings have been used in various ways: as an enabling step, for example Lehtinen and Palli's (2011) videotaping of a series of organizational meetings for further, largely textual analyses; or to study the nonverbal performances such as gestures and facial expression (Manusov \& Trees, 2002). Such studies highlight the importance of bodily expressions as both culturally ritualistic, as well as situation-specific enactments of social relations, employed to structure and order inter-active human affairs (LeBaron \& Jones, 2002) and to enact particular identities (Clarke, 2011). Video data have also been used to study work processes, such as the sequential organizational workflows that constitute call-centre activity systems (Blackler and Regan, 2009) or the ambivalences, struggles and surprises invoked by continuous changes to hospital work settings (Engestrom, 1999). In a similar setting, Hindmarsh \& Pilnick (2007) employed video to analyse teamwork in when investigating how verbal and non-verbal elements of collaborative 
work are interwoven and how embodied practices are sensed and disrupted in the flow of work.

Video studies raise questions about the recording and viewing apparatus involved but also about the role and influence of the researcher (Mumford, 2016). When intervening in the on-going filming process or in choosing static positions for cameras researchers not just record, but actively produce accounts of organizations just as they more obviously do in selecting, deleting, editing and reproducing video sequences. These recorded accounts carry their own possibilities, including those of rewinding and fast forwarding, pausing or zooming, cutting or joining. This double temporality and double spatiality can make certain things visible or meaningful primarily by virtue of being recorded and reproduced, and not necessarily as part of the original (organizational) world from which they are filmed (Pinchevski, 2011: 155).

Epistemologically, video research not only documents but intervenes. Iedema, et al., (2006), actively involve participants in video studies to enact problems not just for observing researchers, but as part of an inquisitive and reflexive journey in which they can act out and subsequently review existing problems, moving beyond limiting decontextualized descriptors. Others invite participants to direct the focus of the inquiry not jut by performing in front of a camera, but also by directing, narrating, and broadcasting their own videos in a fashion close to the work of visual anthropologists (Muir \& Mason, 2012; Gubrium et al., 2014), giving voice (and image) to otherwise muted or othered concerns.

In this emancipatory sense, video studies echo concerns raised by researchers employing diary-based methods. Uses of diaries range from information gathering in the form of semi-structured questionnaires (Louis, 1980) and telephone prompted 
responses (Uy, et al., 2010) to reflexive writing tasks in classroom settings (Cunliffe, 2002). Written diaries are time-consuming and there is the suspicion that the editing of entries leads to sanitized and shortened accounts whilst it has been suggested that audio recorded diaries "encourage more openness, directness and self-expression, and perhaps allow for more emotive observations than written words" (Balogun, et al., 2003: 209).

New approaches to user-generated research combining diaries and videos emerge through the wide availability of smartphones and other camera-equipped devices. However, as yet, few studies using video-diaries in organization and management research exist. One example is provided by Mason (2010) who, while not explicitly analyzing visual aspects, suggests video diaries create the capacity for continued communication over physical distance through the dialogical development of meaning between diarist and researcher. Below, we expand Mason's nascent line of inquiry and assess the utility of video diaries in the study of organizations.

\section{Three illustrative research foci: bodily expressions, identity, practice}

We assess the utility of video diaries for organizational research in three broad research areas: bodily expressions, identity and practice. As a precursor, we offer a brief review of each area to elicit key demands placed on research methods in these specific domains. This review is intended to be indicative rather than exhaustive and in choosing three different research areas we hope to broaden the scope of our evaluation of the relative utility of diaries, videos, and video diaries in each area. 


\section{Bodily expressions}

While effable data readily lend themselves to codification and analysis they are often restricted to verbal systems and discourses (Bell and Davison, 2013). Whether gathered in interview settings or via diary studies, textual data represent only a partial subset of embodied organizational life. One trope of literature has therefore emphasized that we, the individuals populating organizations, are first and foremost 'bodies', imbued with emotions and passions, and thus enacting our world through all of our senses in ways that exceed that which can be linguistically recorded (KnorrCetina, 1997; Strati, 2007).

A focus on bodily expressions is found in a variety of traditions, including studies of gender and sexuality in organizations (see Hassard, et al., 2000), linking 'felt meanings' (Warren, 2008) to sensory experiences especially in form of images and signs (Meyer et al., 2013; Bell \& Davison, 2013). Gestures and facial cues have been recognized as important aspects of communication (Manusov \& Trees, 2002; LeBaron \& Jones, 2002), and the proliferation of audio-visual communication and the widespread availability of imaging, video and networking capabilities (Pauwels, 2010) re-inforces this view. Moreover, some philosophical approaches see perception as not merely tied to some abstract (textual, verbal or ideal) realm but as a bodily phenomenon, where all the senses reach out into the world and are touched by it (Hancock, 2008). Studying bodily expressions begs the question of how transitory phenomena which are "often fleeting, existing tantalizingly beyond our grasp" may be 'pinned down' and evaluated (Warren, 2008: 561). 


\section{Identity}

The second research area we consider, identities in organizations, is both vast and diverse. For our purposes here we focus on aspects of individual (as opposed to group/shared or organizational) identity. Brown (2014: 21) summarises the key research questions in terms of: "the meanings that individuals attach reflexively to their selves as they seek to answer questions such as: 'How shall I relate to others?' 'What shall I strive to become?' and 'How will I make the basic decisions required to guide my life?"' These considerations mark identity as both individual and social since an individual's self conception is bound up with societal hierarchies and roles (Jarventie-Thesleff \& Tienari, 2016), giving rise to questions of fit; taken-forgrantedness; and complex processes of transgression, modification, repair to, or emergence of, identities (Creed et al., 2010; Leung et al., 2014).

Methodologically, studying organizational members' identities demands insights into the complex tapestry of often contradictory socio-cultural accounts in organizations (Creed et al., 2002); as well as into the unfolding dynamics of identity formation, which come to bear when individuals conduct identity work (Alvesson and Willmott 2002; Brown, 2014).

\section{Practice}

The third area of research that we consider investigates organizational practice. This includes a concern for what organizational agents do in their everyday work and how organizational phenomena 'emerge, develop, grow' or fade away, over time (Langley, et al, 2013). Data relating to practice transcend fixed systems of meanings to include processes of semiotic mediation which are not determined by any syntactic system, but by the social and situated context in which signs are read and 
used (Lorino, et al, 2011). Studying the individual elements of such a distributed view of organization means tapping into specific episodes unfolding in local 'epistemic cultures', where knowledge is embedded in specific, local ways and where any sense of meaning is subject to the contingencies and accountabilities of the prevailing situation - which may or may not be how other groups partaking in the wider network operate (see also Brown \& Duguid, 2001; Spender, 1989).

Practice studies typically demand research methods that help document the fine details of naturally occurring interactions (Mondada, 2006) in order to understand, inter alia, the value and character of contemporary work practices (Hindmarsh \& Heath, 2007); the interrelations of mutually constitutive details through which actions and objects gain their significance in particular working contexts; and the relations of these with representations and the politics of organizing (Suchman, 1995; 2000). Practice approaches can also be used to explore more specific organizational activities, for instance in relation to formation and implementation processes (MacIntosh \& MacLean, 2015).

Our brief account of these three research areas illustrates differences in the specific demands placed on research methods. Studies taking seriously bodily expressions require a range of data on bodily performances accompanying sense perceptions, the exhibition of emotions and on various communication signals, which may only appear fleetingly. Studies of identity require data tracking individuals' shifting self-perceptions and expressions as well as the various and complex sociocultural demands placed upon organizational agents and how these are negotiated, successfully or not, over time. Practice studies require data on on-going work processes, often detailing tasks, actions and accompanying sense-making processes which lend meaning to those tasks. 


\section{Evaluating video diaries}

Having surfaced some of the differing demands that particular research themes invoke we now turn to a comparison of methods: written and audio diaries, other video studies and video diaries. We consider the methodological demands made by studies focusing on bodily expressions, identity, and practice in turn, explicating and evaluating the three methods in relation to each. The source material for our comparison comes from existing research for diaries and video studies. Additionally we draw excerpts of data from our own video-diary based study and provide a table for each theme, summarizing key comparative points.

\section{Bodily expressions: diaries}

In terms of bodily expressions, diaries have long been used to track behaviours. In medical studies, diaries help record changes in bodily behaviour in response to medication, diet or exercise. Self-reporting techniques are also frequently used in organizational research, linking objective working conditions to psychosomatic or psychological strain (Daniels, 2006). For instance, Conway \& Briner (2002) asked managers to record their affective responses to breaches in psychological contracts using daily diary entries which reflected feelings using a range of adjectives ranging from anxiety to comfort and from depression to enthusiasm before subjecting these data to statistical analysis. Alternatively, Riach \& Warran (2015) included 'smell diaries' in their study of organizational sensory experiences, asking participants to record audio descriptions of 'smell episodes' at work. This provided some rich insights, for instance into the associations made between smells of food, perfume, or various odours as sensual signifiers for recurring events, times of day, or even expected stress, for instance the smell of coffee signifying that 'we are in for a long night' (Riach \& Warran, 2015: 802). These data 
include participants' voices and not just researchers' interpretations of bodily expressions.

However, there are also a number of acknowledged shortcomings of such selfreporting methods, including mood and bias effects; temperament; as well as the prevailing opinion of others (Daniels, 2006). Sensory experiences are not read from the body directly but mediated through participants' own narrations and therefore subject to their capacity and willingness for self-expression.

\section{Bodily expressions: videos}

Bodily expressions have also been explored through video studies. Llewellyn (2011: 729), for example, dissects the gestures, movements, gazes and utterances of specific interactions constituting gift exchanges, taken from video recordings of ticket sales exchanges in a gallery. The camera was in a fixed position allowing for a detailed view of the counter showing the movements of gallery staff, filmed largely from behind, and the movements and faces of customers, allowing for fine-grained analysis of hand and head movements, as well as the use of objects, in conjunction with spoken words. Jarzabkowski et al., (2015) trace bodily movements and expressions in their video-ethnography of traders, again with a fixed position camera on the trader's desk, affording close-up analysis of facial expressions, hand movements, and the use of objects. Others have used videos to study gestures and visual symbols employed as sources of legitimation for entrepreneurs (Gylfe et al., 2016) or as indicators of the emotive involvement and contagion of organizational agents involved in strategic work such as Clarke (2011). Similarly, Cornelissen, et al., (2012) recorded interactions between two entrepreneurs as part of a broader shadowing study, capturing detailed gestures and facial expressions from a variety of camera angles and positions. 
The level of flexibility in the recording process varies between these studies. While Llewellyn (2011) and Jarzabkowski et al., (2015) use fixed camera positions, which allow for careful and deliberate selection of the recording space as well as (near) autonomous recording, Cornelissen et al.'s (2012) method follows organizational agents in different work settings. This required the continued presence of the researcher and multiple but, perhaps, less mannered camera positions (e.g. on one screenshot, on p. 225, one person is partially hidden behind a monitor while in another, on p. 233, a participant is partly obscured by a filing tray).

\section{Bodily expressions: video diaries}

Our own data contained a large number of emotive expressions, most explicitly from Max, the managing director. The pictorial sequence below is an excerpt from a diary entry recorded in Max's home office. It shows gesturing, strong facial expressions, and obvious elements of body language.
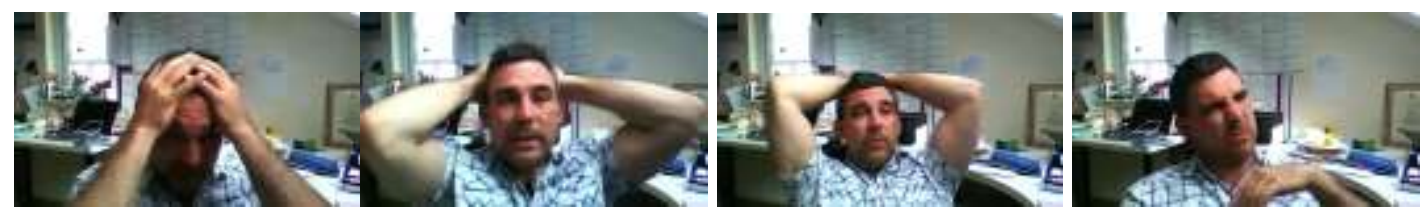

[SEQUENCE A: Max, Entry 2, 10.6.2013: 13.11]

“...you know, I think for me this is the key thing ... is well, how do we manage that? How did we manage the fact that [competitors] are ahead of us and how do we improve? Right, well if that's how it is, well we have just got to suck it up and continue to do what we do as best as we can 'til the message gets out there ... and the clients are the people that count and it's kinda getting over ourselves and kinda getting in front of the clients to be able to drive that 
\{pauses, holds head in hands then leans back\} does this make any sense? (Hmmm)"

The text indicates the tension felt by Max over revenue streams in a fledgling business. The accompanying audio draws out that tension in the tone and hesitancy of Max's delivery. Yet the video imagery, in particular his gestures and facial expressions, indicate the emotional toll of organizational life in a way that neither the transcribed words, or the audio convey. We can contrast the above recording with an entry made ten days later, in which Max is less animated and displays less facial tension:

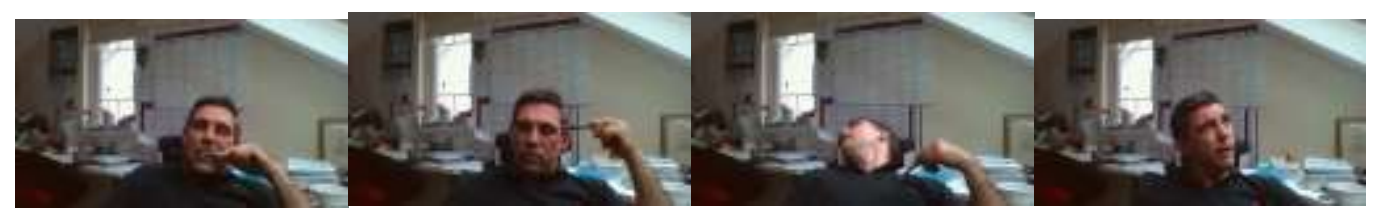

[SEQUENCE B: Max, 20.6.2013 8:31]

“... anyway, that's me, it looks like I'm in a much better frame of mind than I was the last time... I still think we are a little bit in the fucking shit but well, what's the worst that can happen... I don't know if I've told you this but my plan B, if it all falls on its arse, we'll take some equity out of the house that we have and we are going to fuck off travelling for a year. So it doesn't sound like a horrendous thing”

In sequence $\mathrm{B}$, the transcribed text indicates that Max appears less worried than in sequence A. We note the density of expletives which, while not uncommon in this data set, is particularly high. When coupled with the visual data, we felt a sense of despondence if not irony which the text alone did not convey: Max leaning back, staring into space, creates a rather unfocussed impression as he shares a private 
insight to which his organizational peers are not privy. Sequence B contrasts with a third entry, sequence $\mathrm{C}$ recorded only five days later, in which Max appears calm, hands clasped, but this time focused and succinct:

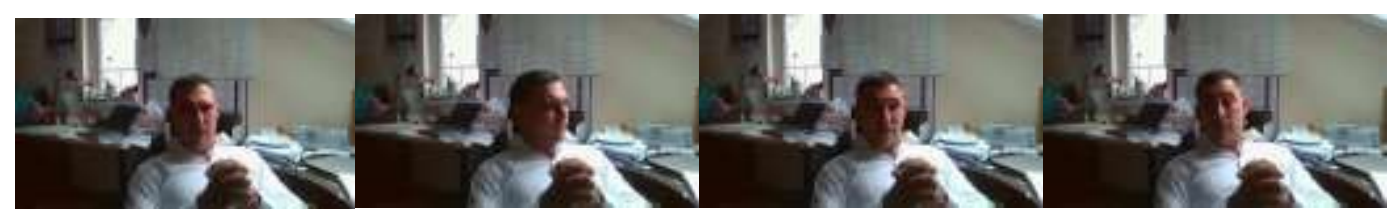

[SEQUENCE C: Max: 25.6.2013: 4.48]

"The technology ticks a lot of boxes and actually, it's funny, [starts rocking slightly forth and back in his chair] we got quite excited about it and we've been effectively trying to punt it to potential clients... They got quite excited about it so I don't really understand how these guys [the sales representatives] have got this fantastic product that they can't actually sell to anyone or that they are just losing money hand over fist."

Bodily expressions also featured prominently in the data provided by a second diarist, Charlie, here deliberating on the future direction of the company:
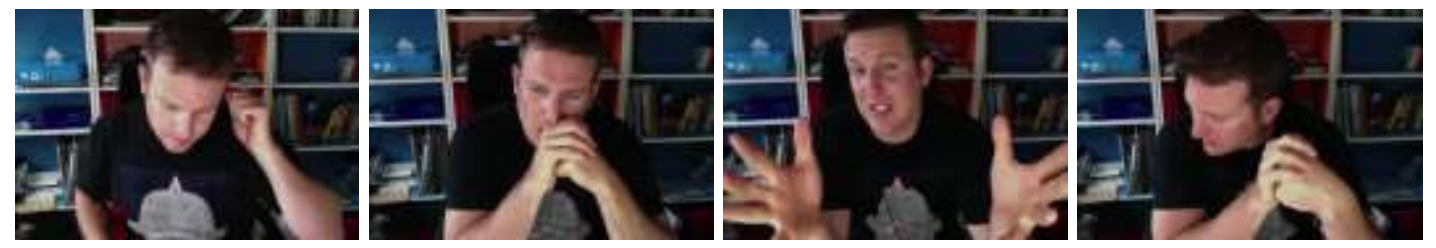

[SEQUENCE D Charlie: 23.7.2013:22.44]

“... I can't help but think in the long term [a licenced product] would be a nice business model. However, are we trying to do too much in the short term? Should we look to get [the software product] out there first and then back it up with all the services behind? That is kind of my thoughts for the last month or 
so \{pause - rests mouth on hands\}. That's my conflict. It's glaringly obvious \{big hand gesture\} that that is my conflict \{looks away\}."

Again transcribed text conveys one account of Charlie's thought processes but the addition of video and audio elements detail a sense of emotional turmoil which the text alone may not. We notice the contemplative, almost resigned way in which he rests his head on his hands, but also that the recording was made late at night in his home office and that he looks tired.

In reviewing the diary entries of both Max and Charlie we found multiple instances emotive bodily expressions, sometimes in close proximity within the same diary entry. In contrast, we found much less data relating to bodily expression from our third diarist, Alan, who trained the camera more closely on his face. Below, even though he makes a pointed remark, he expresses only minimal facial changes whilst speaking in a quiet, measured tone.

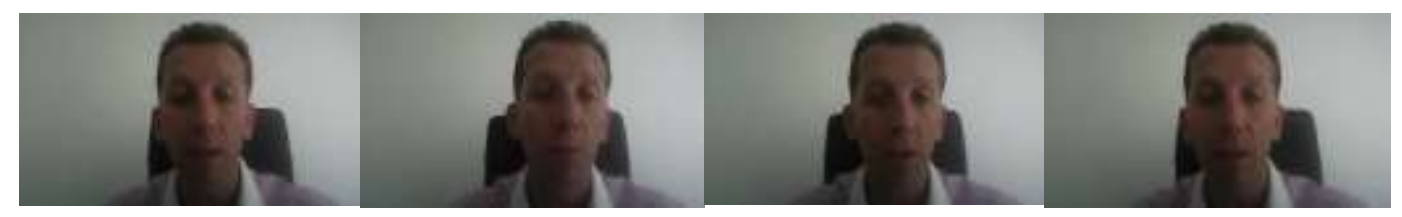

"in general, you know, we seem to be moving forward. I have made the point to all of the guys that if they thought they had been working hard for the last 18 months, well they ain't seen nothing yet because when the investor money comes in they are going to have to work even harder."

[SEQUENCE E: Alan, entry 1, 1.8.2013:2.06]

We were even more surprised by the entries of a fourth participant, Peter, who successfully subverted our attempts to record gestures or facial expressions by using 
an animated graphical representation rather than footage of himself. Sequence F below shows that these avatars conveyed some movement of the head, eyes and mouth but they precluded any more meaningful graphical analysis:

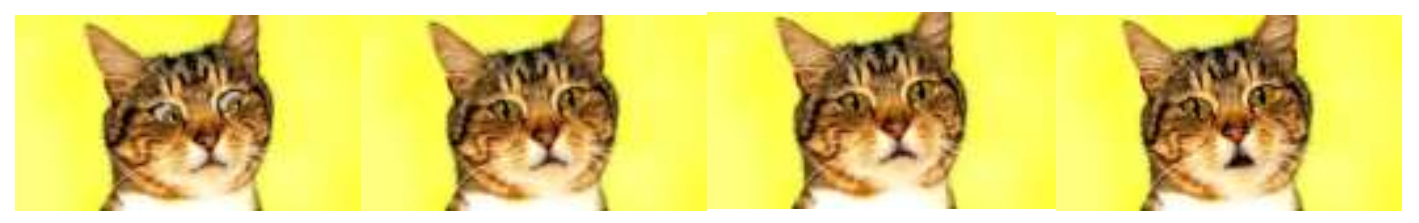

[SEQUENCE F: Peter (entry 1): 20.6.2013: 0.10]

"...the most important thing is, for me at the moment, not for the next few years but for the next few months is surviving this massive gap that we have between projects (ehm) obviously we have projects down the line but it surviving and having enough money so that all of us can pay our mortgage..."

The transcribed text of sequence $\mathrm{F}$ suggests a high degree of emotional concern about the future of the company and the individual. We get a clue to the seriousness of these issues for Peter from his tone on the audio track. However, compared with the expressive gestures and facial dynamics of Charlie and Max's or the more reserved presentation of self from Alan's facial close up, we found much less to work with in the recording of an avatar. Peter did not give any reasons for using the avatar when communicating with us, merely indicating that he found it a 'funny thing to do'.

Table 1: Bodily expressions

\begin{tabular}{|l|l|l|l|}
\hline & $\begin{array}{l}\text { Written/audio } \\
\text { diaries }\end{array}$ & Alternative video methods & Video diaries \\
\hline $\begin{array}{l}\text { Ability to } \\
\text { capture } \\
\text { fleeting } \\
\text { gestures, } \\
\text { expressions }\end{array}$ & $\begin{array}{l}\text { Limited. Written } \\
\text { diaries are prone to } \\
\text { self-editing whilst } \\
\text { there may be more } \\
\text { opportunity to } \\
\text { capture this in an }\end{array}$ & $\begin{array}{l}\text { Reasonable. The } \\
\text { researcher can zoom and } \\
\text { focus if present. The use } \\
\text { of high-definition } \\
\text { equipment, lighting, etc. } \\
\text { might allow micro level }\end{array}$ & $\begin{array}{l}\text { Limited visual data and } \\
\text { restricted to expressions in } \\
\text { post hoc reflections, at least in } \\
\text { our sample data. However, } \\
\text { greater control of data capture } \\
\text { e.g. by specifying camera and }\end{array}$ \\
\hline
\end{tabular}




\begin{tabular}{|c|c|c|c|}
\hline & $\begin{array}{l}\text { audio diary. } \\
\text { A wide range of } \\
\text { sensory experiences } \\
\text { can be referred to } \\
\text { (smell, sound, } \\
\text { sight, etc.) but only } \\
\text { indirectly. }\end{array}$ & $\begin{array}{l}\text { data to be subjected to } \\
\text { analysis. } \\
\text { Primarily focused on } \\
\text { ocular senses but it is } \\
\text { possible to record } \\
\text { reactions to noise or } \\
\text { smell, etc. }\end{array}$ & $\begin{array}{l}\text { respondent position or tighter } \\
\text { control of recorded content } \\
\text { (viz. Peter's disguise) may } \\
\text { improve the ability to capture } \\
\text { such data. More positively, } \\
\text { video diaries may capture less } \\
\text { guarded emotive expression } \\
\text { beyond the formal workplace. }\end{array}$ \\
\hline $\begin{array}{l}\text { Ability to } \\
\text { capture on- } \\
\text { going/ } \\
\text { dispersed } \\
\text { data }\end{array}$ & $\begin{array}{l}\text { Very good. Diarists } \\
\text { can record entries } \\
\text { longitudinally } \\
\text { including places } \\
\text { and times where } \\
\text { researcher is not } \\
\text { present. }\end{array}$ & $\begin{array}{l}\text { Variable. Fixed camera } \\
\text { positions may limit the } \\
\text { possibility of gathering } \\
\text { dispersed data. Where the } \\
\text { researcher is present this } \\
\text { improves the scope for } \\
\text { gathering dispersed data } \\
\text { but this becomes } \\
\text { time/resource intensive } \\
\text { and potentially intrusive. }\end{array}$ & $\begin{array}{l}\text { Very good. Widely available } \\
\text { and easy to use recording } \\
\text { devices can generate } \\
\text { substantial volume and } \\
\text { richness of data by multiple } \\
\text { respondents with little effort. } \\
\text { There are limits to the control } \\
\text { exerted over viewing angles, } \\
\text { focus, time of recording, etc. } \\
\text { as evidenced in our study. } \\
\text { Alternative uses of diaries may } \\
\text { instruct participants to film } \\
\text { others' reactions in the } \\
\text { workplace. }\end{array}$ \\
\hline $\begin{array}{l}\text { Ease for } \\
\text { participant \& } \\
\text { researcher }\end{array}$ & $\begin{array}{l}\text { Variable. Works } \\
\text { well for those who } \\
\text { find the process of } \\
\text { writing diaries } \\
\text { comfortable but } \\
\text { prone to self- } \\
\text { editing processes. } \\
\text { Potentially difficult } \\
\text { to gain both access } \\
\text { and commitment to } \\
\text { participate over the } \\
\text { medium term. }\end{array}$ & $\begin{array}{l}\text { Variable. Video studies } \\
\text { raise concerns about the } \\
\text { extent to which the } \\
\text { presence of cameras } \\
\text { and/or researchers } \\
\text { influence the conduct of } \\
\text { participants. } \\
\text { Access to sensitive } \\
\text { organizational sites is } \\
\text { likely to be difficult but } \\
\text { some studies indicate that } \\
\text { once this has been } \\
\text { secured, data gathering is } \\
\text { not taxing. }\end{array}$ & $\begin{array}{l}\text { Good. Our diarists described } \\
\text { the process of recording video } \\
\text { diaries as convenient, flexible } \\
\text { and in some cases therapeutic. } \\
\text { Initial access is challenging } \\
\text { and may be helped by other } \\
\text { complementary methods (in } \\
\text { our case interviews and } \\
\text { observation). Our study } \\
\text { indicates that this is } \\
\text { exceptionally time efficient but } \\
\text { requires commitment from } \\
\text { participants and that } \\
\text { anonymity is difficult to } \\
\text { maintain. }\end{array}$ \\
\hline $\begin{array}{l}\text { Ethical and } \\
\text { other } \\
\text { practical } \\
\text { consideratio } \\
\text { ns }\end{array}$ & $\begin{array}{l}\text { Reasonable. } \\
\text { Significant ethical } \\
\text { considerations but } \\
\text { relatively easy to } \\
\text { anonymize data. } \\
\text { Audio recordings } \\
\text { may raise } \\
\text { discomfort in } \\
\text { participants and } \\
\text { require some } \\
\text { technical skill and } \\
\text { the use of recording } \\
\text { devices. }\end{array}$ & $\begin{array}{l}\text { Challenging. Anonymity } \\
\text { may be possible unless } \\
\text { the study requires details } \\
\text { of facial expression. } \\
\text { Also, requires filming } \\
\text { equipment, technical } \\
\text { knowledge and aesthetic } \\
\text { input from the researcher. }\end{array}$ & $\begin{array}{l}\text { Challenging. Significant } \\
\text { ethical considerations caused } \\
\text { by difficulty in anonymizing } \\
\text { data and the revelatory nature } \\
\text { of some data. Some evidence } \\
\text { of practical challenges in } \\
\text { creating then uploading a diary } \\
\text { entry. Requires participants } \\
\text { with access to video devices } \\
\text { and, in our case, internet } \\
\text { connections. }\end{array}$ \\
\hline
\end{tabular}




\section{Identity: diaries}

Written and audio diaries present an obvious methodological choice for those studying individual, organizational and professional identity through 'deep analysis of individuals' internal processes and practices' (Radcliffe, 2016), but gaining and keeping access is challenging and there are issues around reliability. Existing research ranges from tightly structured to loose configurations. For instance, Dornan et al. (2015) used audio diaries in a study of trainee clinicians to explore the role of emotions in the identity work involved in becoming a doctor. Diary entries were recorded daily over ten working days against a set of standard prompts generating accounts of emotional attachment and detachment in relation to patients. These data were then subjected to critical discourse analysis. Similarly, in a study of 'illegitimate tasks' Eatough et al. (2016) asked respondents to use established rating scales twice or three times per day to generate numeric data. In contrast, Beech (2011) uses autobiographical diaries, written independent of the research process, in a study of liminalities in identity work. Diaries have also been used to explore a range of topics from identity in safety-related settings (Pilbeam et al., 2016) to multitasking (Mattarelli et al., 2015).

Identity: videos

Studies of identity in organizations have increasingly drawn on video technologies, following the long-standing practice of video-based research in sociology and anthropology (e.g. McDougall, 1997; Prins, 2002). Samra-Fredericks (2010) produced a set of videos of everyday interactions in an organization, generating detailed and granular accounts of 'face' and 'face-work' exchanges. Clarke (2011: 1372) used extensive video observations to identify the visual symbols employed by entrepreneurs when presenting themselves and their businesses to 
various stakeholders. Carefully deliberation of the optimal viewing distance and camera angles, Clarke (2011) attempts to capture 'participants acting naturally'. LeBaron, et al., (2009) analyse episodes of (positive) identity work from video-taped interviews. Here, 'fly-on-the-wall' cameras were placed unobtrusively to provide insights into postures, gestures, stances, expressions and eye gazes between interviewer and interviewee in the continuous negotiation of their identities. Contrasting with these in situ studies, Marsh and Musson (2008: 37) video record interviews conducted with teleworkers to analyse gender identities, arguing that voice recordings alone lacked the 'intimacy and immediacy' required to examine the performative nature of identity.

\section{Identity: video diaries}

Unlike some of the examples above, our video diary study does not contain footage of identity work between actors in the workplace. Instead, recordings detail on-going negotiation of 'selves' within the firm. The diarists in our study, especially Charlie and Max, repeatedly engaged in intense reflections on their roles and the difficulties in sustaining these:

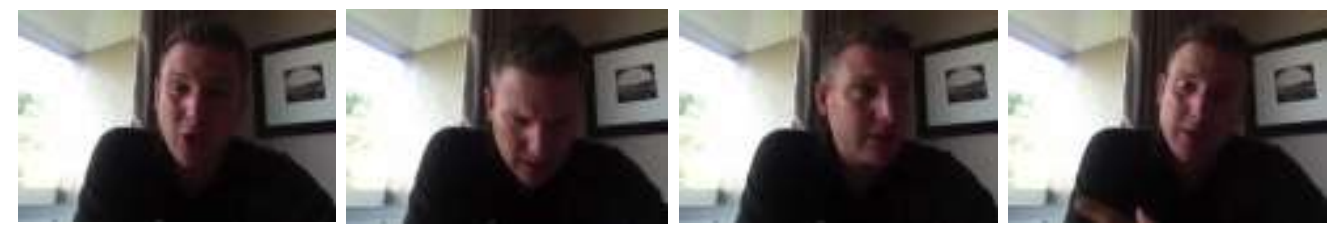

[SEQUENCE G: Charlie, entry 1, 14.8.2013:14.44]

"what we are finding is that obviously we all had this, when we first started the company we had this image of what we wanted to do within it, and what we were and what we weren't going to do. But as we naturally grow, we are 
finding ourselves dropping into... Finding our personalities are changing or our experiences are changing, meaning we are walking down paths that we never expected to be taking or to be taken within the company."

Max, also recorded thoughts about expectations tied to his role as Managing Director, and his concerns in enacting this identity:

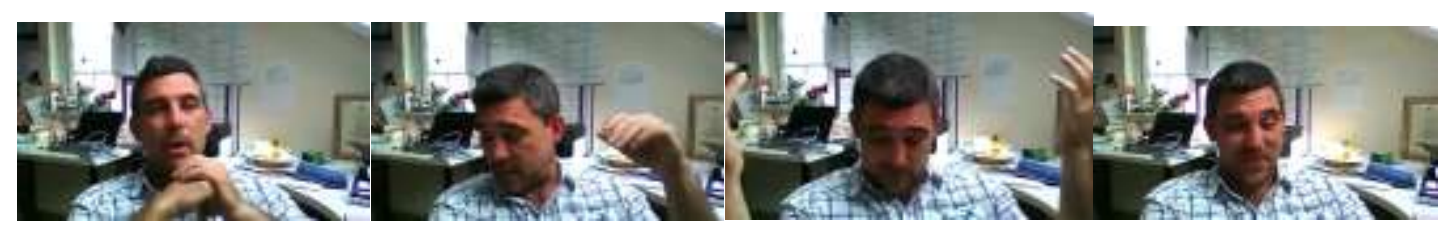

(SEQUENCE H: Max, entry 2, 10.6.2013: 14:14)

“... (urgh) reflecting on it \{smiles\} maybe it's just the general overall worry that I have as the MD that, that, just the worry of the company - whether we are going to make it or not? (ehm )\{looks away from the camera then looks down\} that's my concern and the people around me that say that it's going to be successful, it's going to continue, you know there are some dark moments where it's pretty tough ..."

Sequences $\mathrm{G}$ and $\mathrm{H}$ highlight reflective contemplations on identity and role demands. We also found some examples of on-going identity work, for instance when Max engaged with the (absent) researchers:
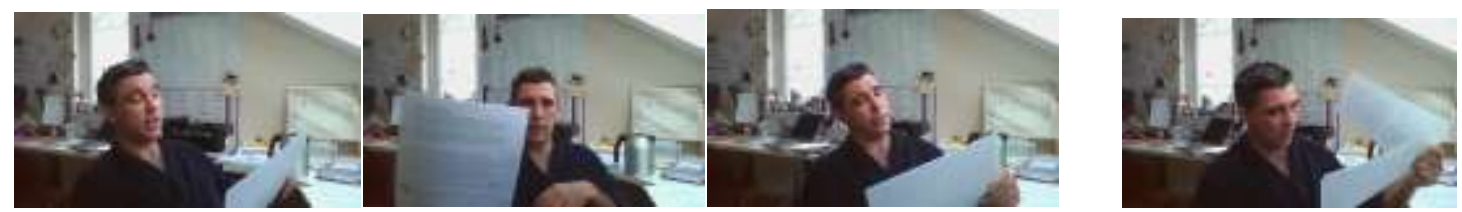

(SEQUENCE I: Max, Entry 1, 16.8.2013: 0.00). 
"Morning [addresses one of the researchers]! It's a lovely day in [location] Hope you are well. This is me talking to the computer which is almost like talking to you. I have my papers here and also have \{reads out academic paper title and holds it to camera\} which is just a fucking awesome title! (uhm) I'm actually quite curious as to the titles you have given your papers to find out if they are as equally pompous and smart arse as these... I see here Messieurs Eisenhardt, Quinn, Weick and... Mintzberg - are all in here - oh there is even Schumpeter as well. I've just printed this out and I am going to read this over the weekend. It will be nice to read a paper again, I actually think I might have missed it (ehm) which is odd (ehm)"

Here Max delineates his identity not vis-à-vis interlocutors from everyday organizational life (as in Clarke's work with entrepreneurs, 2011 or LeBaron's et. al.'s work between interviewer-interviewee, 2009) but rather in relation to the researcher. He stresses his familiarity with academic authors as well as portraying a dismissiveyet-interested stance. While the maintenance of his identity this instance relates specifically to the limited context of the video-diary and his relationship with the academics involved, it still offers a valuable clue as to the complexity of the person that is Max.

We gathered a number of reflective statements about the participants' identities, their ongoing struggles and the wider contexts in which these unfold. Here we found a surprising degree of openness and deep reflection prompted in the video diary process. Already early-on in the study, Max records: 
(SEQUENCE J: Max, entry 2, 10.6.2013: 16:18)

"I'm getting up earlier and earlier to do more work and now I'm sitting here talking to you for 20 minutes when I should be doing a load of other shit... It's quite a nice catharsis I guess (ehm) to be able to do this (ehm) so thank you for listening to my winghy bollocks."

Audio or written diaries might capture similar reflections but in our data the use of props (e.g. showing an academic paper; flicking through it; tossing it aside) as well as being able to see how the participants dressed in different situations, where they worked, how they furnished and kept their environment and how they composed themselves. Moreover, at least in the case of two of our participants, video diaries prompted sustained, critical and sometimes revelatory recordings whose honesty and openness surprised us.

Table 2: Identity

\begin{tabular}{|l|l|l|l|}
\hline & Written/audio diaries \\
\hline $\begin{array}{l}\text { Ability to } \\
\text { conture self- }\end{array}$ & $\begin{array}{l}\text { Very good. Diaries } \\
\text { can prompt reflective } \\
\text { or reflexive } \\
\text { engagement with } \\
\text { identity work }\end{array}$ & $\begin{array}{l}\text { Very good. Researchers } \\
\text { can tailor the recording } \\
\text { (e.g. camera focus/angle) } \\
\text { to capture 'in situ' identity } \\
\text { work. }\end{array}$ & $\begin{array}{l}\text { Limited. Our data suggest } \\
\text { that reflections on self- } \\
\text { conception were present } \\
\text { and prescriptive } \\
\text { instructions might have } \\
\text { generated more such data. } \\
\text { On-going identity work } \\
\text { may also be traceable, for } \\
\text { example by asking } \\
\text { participants to record } \\
\text { entries as soon as } \\
\text { particular events occur. }\end{array}$ \\
\hline $\begin{array}{l}\text { Ability to trace } \\
\text { identity } \\
\text { development } \\
\text { over time }\end{array}$ & $\begin{array}{l}\text { Very good. Diarists } \\
\text { can record entries } \\
\text { longitudinally } \\
\text { including periods } \\
\text { when the researcher } \\
\text { is not present. }\end{array}$ & $\begin{array}{l}\text { Potentially challenging. } \\
\text { Securing access for a } \\
\text { sufficiently long period is } \\
\text { both resource intensive and } \\
\text { may rely on a long-term } \\
\text { commitment from multiple }\end{array}$ & $\begin{array}{l}\text { Very good. The use of } \\
\text { everyday devices such as } \\
\text { phones and tablets meant } \\
\text { that our diarists recorded } \\
\text { in diverse locations over } \\
\text { several months without the }\end{array}$ \\
\hline
\end{tabular}




\begin{tabular}{|c|c|c|c|}
\hline & & $\begin{array}{l}\text { actors. Video installations } \\
\text { in different locations may } \\
\text { be required. }\end{array}$ & $\begin{array}{l}\text { need for consent from } \\
\text { other organizational actors. } \\
\text { Some very reflective and } \\
\text { open entries. }\end{array}$ \\
\hline $\begin{array}{l}\text { Ability to } \\
\text { capture multiple } \\
\text { accounts/roles }\end{array}$ & $\begin{array}{l}\text { Good. This requires } \\
\text { commitment from } \\
\text { multiple participants. }\end{array}$ & $\begin{array}{l}\text { Limited. This may be } \\
\text { resource intensive and } \\
\text { some approaches (e.g. } \\
\text { filmed meetings) do not } \\
\text { lend themselves to a } \\
\text { plurivocal analysis unless } \\
\text { supplemented with other } \\
\text { data. }\end{array}$ & $\begin{array}{l}\text { Very good. We captured } \\
\text { data from multiple diarists. } \\
\text { In addition, we saw each } \\
\text { diarist in multiple role } \\
\text { contexts (office, home } \\
\text { office, on sofa, airport } \\
\text { lounges, etc.) and } \\
\text { recordings featured } \\
\text { frequent comments on } \\
\text { other actors. }\end{array}$ \\
\hline $\begin{array}{l}\text { Ability to } \\
\text { capture } \\
\text { complexity in } \\
\text { the environment }\end{array}$ & $\begin{array}{l}\text { Limited. Largely } \\
\text { dependent on the } \\
\text { extent to which } \\
\text { diarists choose or are } \\
\text { able to "reveal" such } \\
\text { complexities. }\end{array}$ & $\begin{array}{l}\text { Variable. Depending on } \\
\text { geographical distribution } \\
\text { of work. The need for } \\
\text { researchers' presence or } \\
\text { pre-determined camera } \\
\text { positions limit what is } \\
\text { recorded. }\end{array}$ & $\begin{array}{l}\text { Moderate. Perhaps more } \\
\text { effective than other diary } \\
\text { techniques since it captures } \\
\text { additional visual clues, e.g. } \\
\text { dressing down at home, } \\
\text { posture, etc. We were } \\
\text { struck by the types and } \\
\text { frequency of revelations } \\
\text { about arguments, agendas, } \\
\text { etc. but there remains a } \\
\text { heavy reliance on what the } \\
\text { diarist chooses to reveal. }\end{array}$ \\
\hline $\begin{array}{l}\text { Ease for } \\
\text { participant \& } \\
\text { researcher }\end{array}$ & $\begin{array}{l}\text { Excellent. Easy to } \\
\text { administer though } \\
\text { requires effort for } \\
\text { participants (esp. } \\
\text { writing) which can } \\
\text { make longitudinal } \\
\text { data problematic. }\end{array}$ & $\begin{array}{l}\text { Moderate. Autonomous } \\
\text { recording is possible using } \\
\text { fixed cameras but this } \\
\text { limits flexibility/reach. } \\
\text { Requires equipment, } \\
\text { technical/artistic know } \\
\text { how and multiple } \\
\text { permissions. }\end{array}$ & $\begin{array}{l}\text { Good. Diarists reported } \\
\text { that it was convenient to } \\
\text { record and entries showed } \\
\text { a frankness in the data that } \\
\text { we did not expect to } \\
\text { capture. }\end{array}$ \\
\hline $\begin{array}{l}\text { Ethical and } \\
\text { other practical } \\
\text { considerations }\end{array}$ & $\begin{array}{l}\text { Simple. Potentially } \\
\text { revealing information } \\
\text { but this is easy to } \\
\text { anonymize. }\end{array}$ & $\begin{array}{l}\text { Moderate. Sensitive } \\
\text { information is more } \\
\text { difficult to anonymize. }\end{array}$ & $\begin{array}{l}\text { Complex. Sensitive } \\
\text { information about both } \\
\text { individuals and } \\
\text { relationships is more } \\
\text { difficult to anonymize. }\end{array}$ \\
\hline
\end{tabular}

\section{Practice: diaries}

Studies of organizational practices typically concern the embedded and situated nature of activities but diary studies are not frequently used in this field. Green and Cluley (2014) study innovation using practice theory and gathered diaries as one part of a wider data set comprising field notes, observations and other sources data collected as part of a longitudinal study. Radcliffe (2013) employed diaries to investigate the complexities of negotiating the boundaries of work in terms of the 
negotiation of work-life decisions while Plowman (2010) asked participants to record individual self-reflections on daily events to look below the official organizational sphere. Diedrich and Guzman (2015) use diary data to study organizational practices relating to knowledge management though more of their analysis draws on standard interview techniques and other methods rather than on diary entries per se. Finally, in the context of marketing practices, McColl-Kennedy et al. (2015) use diary data to explore the co-creation of service experiences. Diaries then can be particularly helpful since they can accommodate respondents from different communities of practice.

\section{Practice: videos}

In contrast to the paucity of diary studies of organizational practice, visual technologies are increasingly recognised as affording a better appreciation of the 'situatedness' of organizational activities (Chia \& Rasche, 2009: 714). One trope of work uses videos to bring together micro or agentic elements with more macro or structural aspects. Examples include Gylfe et al.'s (2016) use of videos to illustrate how participants bridge individual concerns into wider strategic directives, whilst Engestrom (1999) uses videos to visualise phenomena that link individual actions with wider, group or communal activities. Videos may invite discussion between practitioners and researchers about 'troublesome work situations'. For example, Iedema, et al., (2006), employ videos to involve participants in the resolution of organizational problems by highlighting what may otherwise remain obscure, taken for granted, or veiled behind definitional language. Once recorded, ordinary elements of work practices can be revisited such that 'different aspects' (Iedema et al., 2006: 24) dawn on those involved, allowing the situation to move on.

Video studies which focus on interaction and work coordination can place the body centre-stage (see Hindmarsch and Pilnick, 2007). Their study affords an 
intriguing insight into the orchestration of human bodies and objects in an operating theatre, disrupting any ideas about the stability of 'teams' and, instead, showing how work is practically accomplished through embodied practices.

Video data are also being used in the spirit of ethnographic work where researchers are 'there' or even participating in the actions for those studied (Smets, et al., 2015). Liu and Maitlis (2014: 2066), for example, video-record a series of top management meetings to identify and analyse their constitutive micro-behaviours and interactions. Proponents of video data suggest that video offers a "faithful record of the data long after the fieldwork is finished, allowing repeated scrutiny of important episodes during the data analysis stage" (opt cit.).

\section{Practice: video diaries}

Our video diaries only limitedly detailed problems in work patterns in the ways in which, for example, Engestrom (1999) or Iedema et al.'s (2006) studies allowed. Neither could our data speak to bodies at work in the way in which Hindmarsh and Pilnick's (2007) study did since we did not capture images of in-situ work activities. Instead, video diaries allowed us to glimpse these managers' nonpublic work-spaces, enriching our sense of the places, spaces and times in which their work occurred, at work, in their home offices or in hotels.

Moreover, the video diaries efficiently traced otherwise hidden organizational events and the associated sensemaking processes. One example is a serious row between Max and Charlie, which happened at a private meeting and which Alan, Max and Charlie discussed, at different times, in their recordings. Following what Gylfe et al., (2016) call 'patterning' we present a combination of excerpts relating to that specific organizational episode. Max states that: 
“(ehm) I had a massive row with Charlie, (ehm) basically I've been on his case for two weeks - I don't think he's been performing particularly well, I think he has been tossing it off (ehm) this has been frustrating me (ehm) [30 seconds omitted for ethical reasons] ... Charlie and I, we had this massive row, but the problem is he's just had a baby (ehm) Peter's got a baby and they are my two business partners (eh) well Peter's son is five (ehm) so they've got these kind of divergent priorities.. I don't have kids (ehm) and I'm willing to basically probably make myself sick to make this work (ehm) but I don't think they are (ehm) and how do I manage my own expectations (ehm) in this regard?"

[Part of SEQUENCE H, for images see above: Max, entry 2, 10.6.2013:14.40]

The event is picked up by Alan in an entry only three days later:
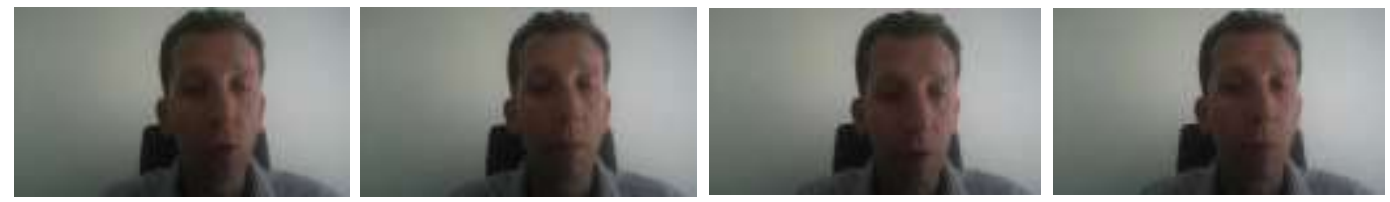

[SEQUENCE K: Alan, 13.6.2013:2.58]

“'shifts in seat\} Max and Charlie have had a couple of (ehm) 'Set To's' on different things, mainly because Max is very focused and seems to be working 24/7 on the business. Charlie married in the course of the last couple of years, with a three-month old baby, priorities have changed a bit and (eh) (ehm) that seems to be causing some challenges. I knew it was tense but wasn't aware how much until something blew up out of nothing the other day, so I've been speaking to Max about that, trying to give a bit of guidance on what we should 
do with that and how we can move that forward because its, its vital that we get that sorted out."

Neither Peter or Charlie refer to the row directly, but both provide entries which, at least indirectly, acknowledge the clash of expectations and personal circumstances. Around six weeks after the row, Peter, this time using a different avatar, records:
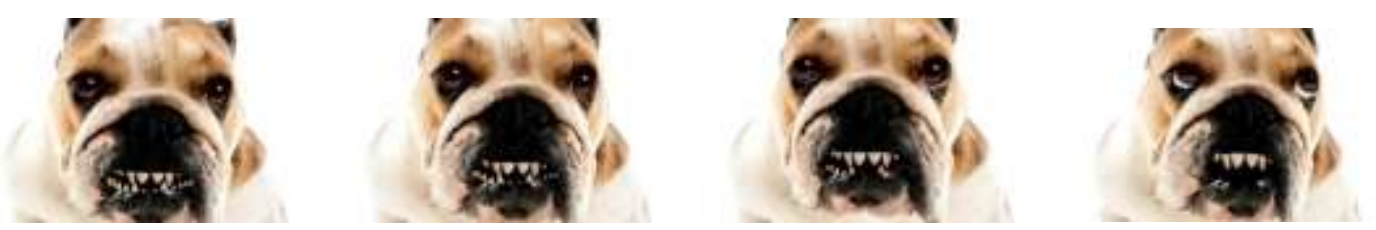

(SEQUENCE L, Peter, entry 1, 2.8.2013:2.33)

"I'm going to get more involved because I always seem to be out on a limb at the moment on my own. But now I will be more involved with Charlie - give him a hand as well because I've felt he's been feeling quite left, well not left to do it all on his own but last week we had quite a lot of work on and I wasn't able to help him because I was in [location] with prior arrangements i.e. my son's birthday, which he understood, which is good, but now I can come up here and relieve the load and bounce ideas off each other, because we all seem a bit distant."

Charlie himself comments on his engagement around two months after the row as follows:

"It has been very difficult working remotely as a team on different projects ... [looks down] we have just had a little boy, and that has been difficult, predominantly working from home. Max is up in (a northern UK city), Peter is down in (a southern UK region), Alan is in (northern UK city), projects are 
spread around the UK. It has been very difficult to get in the office to bounce ideas around, everything is done by email, everything is done by phone, it is just dragging things out. It's kind of misinterpreted by the way people type misinterpretation of emails or text messages, working remotely, can't see people's faces, can't read their emotions (ehm)\{pause, has pained expression\} it kind of creates a very fractious, stressful environment in which to work. Especially with the uncertainty and that kind of... striving to be successful with the company." (for images see Video Sequence G above, Charlie, Entry 1 14.8.2013: 10.49)

A number of interesting insights can be drawn from these fragments of video diary data. First, while our video diaries do not contain actual footage of the disagreement, or of any associated work processes or problems encountered, they do elicit different accounts tied seemingly to the same 'event'. Not all of the management team witnessed the event directly; nor did we as researchers, yet we do have multiple perspectives captured at multiple points in time. Second, the data offer direct and timely comments on the row (from Max and Alan) as well views that discuss related and underlying tensions around expectations and demands (see entries from Peter and Charlie) which surface weeks or months later. Third, while Peter disguised his image using an avatar and Alan's close focus recorded only minimal additional movement, it is clear from the serious and at times pained expressions of Max and Charlie that this was an emotionally charged experience.

The obvious drawback of video diaries, at least in the way in which we configured the research, is that it does not provide the kind of rich data on microbehaviours and interactions Liu \& Maitlis (2014) captured, yet the example of the disagreement above shows that we did elicit aspects of group interaction, sanctions, 
different views on the issues at hand.

Table 3: Practice

\begin{tabular}{|c|c|c|c|}
\hline & Written/audio diaries & Alternative video methods & Video diaries \\
\hline $\begin{array}{l}\text { Ability to } \\
\text { record work } \\
\text { activities }\end{array}$ & $\begin{array}{l}\text { Partial. Diaries allow } \\
\text { individuals to record } \\
\text { perceptions, sometimes in } \\
\text { the form of the stories } \\
\text { they tell themselves and } \\
\text { others. Whilst capturing } \\
\text { events, this is } \\
\text { retrospective and } \\
\text { therefore subject to } \\
\text { filtering. }\end{array}$ & $\begin{array}{l}\text { Variable. The key issue is } \\
\text { the extent to which } \\
\text { activities happen "on } \\
\text { camera". The presence of } \\
\text { researcher to direct camera } \\
\text { work is resource intensive } \\
\text { and may influence what is } \\
\text { observable. }\end{array}$ & $\begin{array}{l}\text { Limited. Our design did not } \\
\text { capture workplace activities } \\
\text { though others (e.g. Holliday, } \\
\text { 2000) overcome this } \\
\text { limitation. Questions arise } \\
\text { over consent and disclosure of } \\
\text { sensitive information to other } \\
\text { diarists. }\end{array}$ \\
\hline $\begin{array}{l}\text { Ability to trace } \\
\text { practices over } \\
\text { time. }\end{array}$ & $\begin{array}{l}\text { Very good. Diarists can } \\
\text { record entries } \\
\text { longitudinally including } \\
\text { periods when researcher is } \\
\text { not present. }\end{array}$ & $\begin{array}{l}\text { Variable. The resource } \\
\text { intensive nature of the } \\
\text { process and the need for } \\
\text { multiple permissions may } \\
\text { pose a challenge but on- } \\
\text { going fixed camera } \\
\text { installations are easy to } \\
\text { maintain. }\end{array}$ & $\begin{array}{l}\text { Variable. Our illustrative data } \\
\text { demonstrate that we can trace } \\
\text { single events from multiple } \\
\text { perspectives over time in an } \\
\text { efficient manner but in } \\
\text { absence of actual recordings } \\
\text { of work practices. }\end{array}$ \\
\hline $\begin{array}{l}\text { Ability to tap } \\
\text { into multiple } \\
\text { communities } \\
\text { of practice }\end{array}$ & $\begin{array}{l}\text { Variable. Multiple } \\
\text { accounts can be curated } \\
\text { and 'hidden' events may } \\
\text { be traced but this is } \\
\text { dependent on the richness } \\
\text { of the diarist's } \\
\text { description. }\end{array}$ & $\begin{array}{l}\text { Limited. Even with } \\
\text { comprehensive footage } \\
\text { which captures specific } \\
\text { events (e.g. a meeting or a } \\
\text { shop-floor) there is limited } \\
\text { opportunity to gain } \\
\text { insights into the views of } \\
\text { individuals. Video } \\
\text { installations in different } \\
\text { sites may be required. }\end{array}$ & $\begin{array}{l}\text { Good. Our illustrations } \\
\text { demonstrate multiple accounts } \\
\text { both at the time of an episode } \\
\text { and reflexive } \\
\text { sensemaking/sense breaking a } \\
\text { various points after the event } \\
\text { occurs in a highly efficient } \\
\text { manner. Our recordings lack } \\
\text { the contextual and event- } \\
\text { specific details of other video } \\
\text { formats and offer only limited } \\
\text { additional visual clues about } \\
\text { place, space and state of mind. }\end{array}$ \\
\hline $\begin{array}{l}\text { Ease for } \\
\text { participant \& } \\
\text { researcher }\end{array}$ & $\begin{array}{l}\text { Highly efficient. Written } \\
\text { diaries can be time } \\
\text { consuming to compile but } \\
\text { they provide convenience } \\
\text { for the researcher. The } \\
\text { same is true for audio } \\
\text { diaries. }\end{array}$ & $\begin{array}{l}\text { Moderate. Potentially } \\
\text { difficult to secure approval } \\
\text { to video in-situ practices, } \\
\text { especially at higher } \\
\text { organizational levels. } \\
\text { However, video data can } \\
\text { make problems in actual } \\
\text { work-flows visible and can } \\
\text { lead to resolution. }\end{array}$ & $\begin{array}{l}\text { Efficient. Modest technical } \\
\text { problems occurred in our } \\
\text { study but the process of } \\
\text { recording appeared to } \\
\text { stimulate reflexively. Less } \\
\text { onerous than written diaries } \\
\text { but generates issues in } \\
\text { choosing what to feed back to } \\
\text { the whole management team } \\
\text { based on individual and } \\
\text { sensitive diary entries. }\end{array}$ \\
\hline $\begin{array}{l}\text { Ethical and } \\
\text { other practical } \\
\text { considerations }\end{array}$ & $\begin{array}{l}\text { Simple. Relatively easy to } \\
\text { anonymize. Issues may } \\
\text { arise over } \\
\text { conflicts/disagreement/ } \\
\text { grievances revealed in } \\
\text { diaries. }\end{array}$ & $\begin{array}{l}\text { Moderate. Potentially } \\
\text { revealing information is } \\
\text { more difficult to } \\
\text { anonymize. }\end{array}$ & $\begin{array}{l}\text { Complex. Difficult to } \\
\text { anonymize and our data } \\
\text { featured multiple instances of } \\
\text { sensitive views being captured } \\
\text { which diarists did not want } \\
\text { shared. }\end{array}$ \\
\hline
\end{tabular}




\section{Discussion}

In this paper we assess the utility of video diaries as a method for organisational research. We ask which, if any, additional organizational phenomena video diaries might elicit and how the approach compares with other, adjacent research methods. Thus far we have illustrated specific differences between video diaries, written/audio diaries and other, non-diary video techniques as used in the study of bodily expressions, identity and practice. Next we broaden our discussion to reflect wider concerns about video diaries in recording selective or unselective materials; to be compellingly arranged into flows of events; and to be manipulated to elicit additional insights.

\section{(Un)selective recordings}

Video diaries seem particularly suited to recording reactions and sense-making processes, in parallel, over time, in various geographical locations, and in a manner which is highly resource efficient. Like most technological recording methods, video diaries are 'unselective inscription devices' (Pinchevski, 2012), recording intentional elements alongside unintentional ones. Unlike video recordings operating with deliberatively chosen and fixed camera positions which record more or less randomly occurring behaviours, our video diaries resulted in a range more or less random camera positions, angles, and foci, recording more intentionally guided content following our (minimal) instructions. Unlike written or audio diaries, these additional, unselective elements allowed glimpses into wider working contexts, such as home offices, living rooms, and we saw how they dressed and carried themselves. These unselectively recorded, additional cues gave us a greater sense of various and sometimes conflicting roles being enacted. Unintentionally recorded data allowed us to re-use these recordings to investigate elements we did not build into our initial 
research design. In framing the study we did not have bodily expressions, identities, or visual elements of organizational practices as our primary focus but these additional and unselectively recorded data allowed for relevant analyses.

Unselectively recorded data also offer the possibility of research following a psychoanalytical line of enquiry. The capacity to re-play voices lend audio recordings access to subconscious processes, by recording, processing and transmitting back what may at first seem like nonsense or that which once swept past unnoticed (Benjamin, 2008: 28; Kittler 1986: 89). Relatedly, sequence J, shows Max calling his recoding process 'cathartic'. Holliday (2000) detects similar therapeutic functions in her study of video diaries when individuals question, elaborate, or secure their discursive and social positions via an invisible other as a facilitator of emotion. Invoking this register, Pinchevski (2012: 144/5) investigates video testimonies by holocaust survivors and suggests this medium is capable of capturing and reproducing the fleetingly unconscious and unarticulated traumatic past of the holocaust, precisely by recording silences in addition to what is said.

But also we, as researchers and viewers, found video diaries to be a powerfully affective medium. We experienced video diaries as a medium through which we could record data for research as well as a medium as such; as spaces of "visible and audible dynamic activity' Lemke (2007: 40) to which we, as viewers, respond when making meanings or experiencing feelings. In following our diarists for a few weeks we felt that the recordings transmitted aural or perhaps 'created' elements which we struggled to capture in our analysis.

\section{(In)consistencies}


Video diaries allowed us to record a variety of comments from different participants over time and from geographically dispersed locations. The ease of video editing software allowed us to then set these into specific arrangements, such as our unfolding commentary on the conflict between Max and Charlie (sequences $\mathrm{H}, \mathrm{K}$ and L) or Max's changing emotional state (sequences A, B \& C). Not only were we able to link different diarists together: at home, in the office; in different parts of the country and over lengthy periods, we were also able to create, as we felt, compelling audio-visual sequences which offered visual illustrations of the connections we detected.

Initially, we were almost seduced by a sense that through these diaries we were given an insight into the organization as a whole; that we would be looking at consistent episodes which hung together naturally and which we merely revealed through the video diaries. However, the longer we worked with the data the more we came to realize that the clips did not necessarily 'stand for' the months of organizational time, the various places or people involved. Gibson (2005) argues that whilst video diaries suggest far greater autonomy for research respondents, researchers remain co-producers of any generated data and we had to remind ourselves that there were long pauses between entries, that the clips veiled the geographic distances and that we created many omissions when we reduced 258 minutes of recordings to the few examples presented here. In this regard, video diary data are no different to other methods, including written and audio diaries and other forms of video recordings. However, video diary clips are particularly easy to transform otherwise discrete sequences into 'flows' (Williams, 2004: 87). Setting Max and Charlie's argument into a flow allowed us to direct attention and convey a mood; in the same way in which the flow of Sequences A, B, and C we deliberately 
arrange discrete events to highlight changes in the emotional tone. Through this, we, as researchers were as much creating insight as we were being given it by both our data and our handling of those data. As such there is a particular danger that these flows create their own internal consistencies which are not necessarily the same as the naturally occurring structure of the unfolding events (ibid: 118).

\section{Manipulation}

This leads us to consider more widely the influence of the media-technological apparatus, camera set-up and digital files, the computer keyboard and trackpad, screen and speakers, and the software for fast forwarding or pausing are actively involved in translating 'recordings' into new forms of inscription. Through this process, videoediting processes can bring out "aspects of the original that can only be accessed by the lens" (Benjamin, 2008: 6). We can join together events, manipulate flows of time and place, reverse, hold still or zoom into a sequence in ways which allow us to find ever-new details. This kind of 're-viewing' makes it possible to revisit a record with a different 'set' of purposes which draw out many more noteworthy details than we could have spotted by physically being there in the recording process (Lemke, 2007: 44). The changes in expression in sequences A, B \& C only became clear to us when we watched the different clips; Max's gestures look quite dramatic in the still shown in Sequence $\mathrm{H}$, and created a more powerful reaction in us than occurred when watching the running video.

Pinchevski (2012: 147) suggests that nothing just sits there waiting to be recorded or stored, but that the technology, the entire apparatus of recording, editing, storing, displaying, conditions the very structure of the 'audiovisual mark' of bodily expressions, identity or practice. We suggest that video recording and editing 
produces as much as it records events. In manipulating such data, even though they are audio-visually moving and compellingly 'real', we increasingly abstract them from the lived world from which they were recorded. The process of producing stills, rearranging or zooming in makes it increasingly difficult to re-translate these entries back into the context from which they were extracted. We felt this when, at first we found ourselves affectively arrested by the diary entries presented here, but by watching them over and over again; fast-forwarding or pausing, making stills for the purposes of this paper inured us to the point where we treated them just as 'data' (Lemke, 2007: 46) and we ended up talking about them primarily in terms of sequence numbers, dates, and time stamps (Ernst, 2013: 157), and less clearly in relation to how these moments mattered to those in the organization.

\section{Conclusions and recommendations}

In this paper we have investigated the utility of video diaries. We found the technology both enabling as well as restrictive in each research context: bodily expressions, identity and practices, respectively. The benefit of video diaries over written and audio diaries is that they 'unselectively' record additional visual data. Compared to alternative video methods, video diaries offer an efficient means of gathering data from multiple respondents over time. We were able to capture data that would enable studies of bodily expression, identity and practice associated with their various roles in places which are ordinarily difficult for a researcher to access. The examples shown earlier indicate the rich and unexpected reflections our diarists shared (e.g. Max on the requirements of being a managing director; Charlie and Peter on how to combine family and work life). Further, we have shown how video diaries 
can trace complex issues over time and across various sites from formal work spaces to private homes.

In our particular study, these insights were offset by the lack of in-situ footage of organizational practice, enacted identities, bodily arrangements and expression in everyday organizational practice. We did not pre-specify camera positions or intervene when entries went off track. A more rigid set of instructions and control mechanisms may avoid recordings such as those of Alan or Peter, both offering little scope for visual analysis, but this may come at the price of losing the free, open and revelatory insights that came out when Max and Charlie in particular went off script. Moreover, we note that even though the data we collected were particularly compelling, consideration has to be given to how the technological apparatus involved mediates these data. Even though they are animated and engaging, these data are still re-presentations of organizational life and are both enabled and constrained by the capacities of specific recording and display devices. As the first structured evaluation of video diaries, we conclude with five recommendations for those considering the use of video diaries in their own research.

First, we found video diaries insufficient as a stand-alone methodology for studying organizational practices, at least in the open and unstructured way in which we configured our research. While one participant (Alan) was very structured in his comments, our other diarists frequently veered off topic making it difficult for us to integrate or align insights with the unfolding everyday events in the organization that we were studying, such as won or lost contracts, the acquisition of additional funding, or on-going product development. We realized how critical to our interpretations of 
the diary entries the additional interviews, observations and various collected artefacts were as they allowed us to relate relatively unstructured data to key reference points, jargon, events and event structures. The key benefit of video diaries for the study of organizational practices lay in their capacity to collect reflections from a number of participants in close temporal proximity to unfolding organizational events over time in an efficient way. We therefore suggest that while video-diaries can be immensely helpful and effective means of gathering spatially and temporally distributed data, they are perhaps best used in combination with other research methods that better capture the sequential structure of events and which offer the researcher opportunities to clarify issues or redirect attention in the data gathering process.

Second, it may be possible to expand the utility of video diaries for practice research by providing more focused instructions, for example by asking participants to document their work surroundings or organizational processes. Examples include projects of digital story-telling in the area of public health (Gubrium et al., 2014) or participant-produced digital footage of family Christmases (Muir \& Mason, 2012), whereby research subjects are given the space both in front of and behind the camera, directing, narrating and broadcasting their videos. Such approaches follow, more generally, the work of visual anthropologists such as Ginsburg (1991) whose 'indigenous media' include examples of indigenous people being asked to film themselves in order to self-present their culture; or the provision of video technology to an indigenous community with the largely political aim of providing and broadcasting voice to these peoples (Turner, 1992). While such initiatives have not been without criticism (e.g. Boyer, 2006), they nevertheless point towards the 
potential for video diaries to transcend the strictures of objective, explanatory theory as well as the hegemonic influence of the researcher.

Third, our study emphasizes the need to establish trust in the researcherresearched relationship. We had the most established relationship with Max and, while our other diarists agreed to participate, their level of openness varied significantly as indicated even in the confines of the few excerpts of data presented in this paper. We therefore suggest spending time and effort in developing a shared set of expectations and boundaries with each participant, and to review these regularly, so as to ensure that sufficient privacy is granted while still providing the required level of detail for the research process. We also chose to feed forward in our study, identifying emerging themes which we wanted to hear more about. Clarifying those dimensions of your study which will be fixed and those which will be fluid is particularly important in relation to video diary research.

Fourth, we were surprised by the level of disclosure provided by some of our diarists. We accumulated data which included private information and details, if not confessions about their work, family and personal lives ; most of which we chose not to put into this paper. One point to consider here is the degree to which any such information is shared between participants or fed back to the organization and to individuals. Our research design was clear on the ethical issues around non-disclosure of diary entries between the participants. What surprised us was the extent to which deeply personal information influenced organizational decisions in ways which we could not disclose to others within the organization or commit to a paper output. In some forms of action research this would present the researcher with a dilemma as 
they struggle to balance the rights of the individual diarist with the desire to make improvements in the organizational context. Another point concerns the question of how we, as researchers, deal with sometimes deeply engaging diary entries, especially as we became emotionally attached to the diarists over time. This sense in which attachment and objectivity come into tension is true in other forms of research and there are some discussions on the impact of friendship on research relationships (see Beech et al., 2009), but video diaries place the researcher in a particularly passive spectator role. Thus, a substantial concern are questions of whether, how and when we, as researchers, might intervene if we review recordings that indicate tensions, illegal practices, or which highlight concerns about the well-being of the participants.

Finally, we suggest paying particular attention to the practicalities of the recording process. We asked participants to use their own recording devices and provided access to a private YouTube channel. We encountered a number of problems in the recording process, including failed entries (see Sequence M, below). This raises the very real possibility of losing content or eroding the commitment of participants as is indicated by the visible and audible frustration of Max.

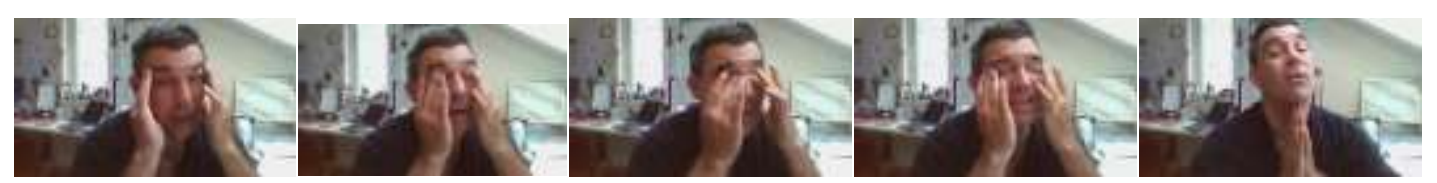

SEQUENCE M: Max, entry 2, 16.8.2013: 0:00

" $\{$ rubs face\} Oh [name of researcher]. Right this is the third time I've uploaded this hopefully. The first time, it crashed but I hadn't got that far. The second time I (pause) I was about 12 minutes into it, so that is really, really fucking annoying." 
Video diaries have the capacity to significantly enrich organizational research. Using the tropes of bodily expressions, identity and practice we have illustrated key benefits and drawbacks of this method and we have shown that they represent efficient and effective means of gathering asynchronous data from different participants in places and spaces beyond the formal organization which are often difficult to reach. In particular the depth of the revelations in our video diaries surprised us and the facility to imbue textual data with an emotive tonal palette struck us forcefully as a way of enlivening and enriching organizational research accounts. Video diaries also offer a way of impacting organizational practice, not only through feedback processes, but also by providing an invitation to pause and reflect. We hope to see further studies exploring the possibilities generated through the availability of video technology. 


\section{References}

Alvesson, M. \& Willmott, H. (2002) Identity regulation as organizational control: producing the appropriate individual. Journa of Management Studies, 39(5): 619-45.

Balogun, J., Huff, A. S., \& Johnson, P. (2003). Three responses to the methodological challenges of studying strategizing. The Journal of Management Studies, 40(1), 197224.

Beech, N., Hibbert, P., MacIntosh, R. and McInnes, P. (2009) But I Thought We Were Friends ?, in S Ybema, D Yanow, H Wels and F Kamsteeg (eds), Organizational Ethnography: studying the complexities of everyday life, SAGE: London, Chapter 10, 196-214.

Beech, N. (2011) Liminality and the practices of identity reconstruction. Human Relations, 64(2): 285-302.

Bell, E. and Davison, J. (2013), "Visual management studies: empirical and theoretical approaches", International Journal of Management Reviews, Vol. 15 No. 2, pp. 167-184.

Benjamin, W. (2008) The work of art in the age of mechanical reproduction. Transl. J.A. Underwood. London: Penguin.

Blacker, F. \& Regan, S. (2009) Intentionality, agency, change: Practice theory and management. Management Learning, 40(2): 161-176.

Boyer, D. (2006) Turner's anthropology of media and its legacies. Critique of Anthropology, 26(1): 47-60.Chirban, J., T. (1996). Interviewing in Depth. Thousand Oaks: Sage Publications. 
Brown, A.D. (2014) Identities and identity work in organizations. International Journal of Management Reviews. 17: 20-40.

Brown, J.S. \& Duguid, P. (2001) Knowledge and organization: A social practice perspective. Organization Science, 12(2): 198-213.

Chia, R. \& Rasche, A. (2009) Researching strategy practices: a geneaological social theory perspective. Organization Studies, 30(7): 713-734.

Clarke, J. (2011) Revitalizing entrepreneurship: How visual symbols are used in entrepreneurial research. Journal of Management Studies, 48(6): 1365-1392.

Conway, N. Briner, R.B. (2002) A daily diary study of affective responses to psychological contract breach and exceeded promises Journal of Organizational Behavior, 23: 287-302).

Cornelissen, J., Clarke, J. \& Cienki, A. (2012) Sensegiving in entrepreneurial contexts: The use of metaphors in speech and gesture to gain support for novel business ventures. International Small Business Journal, 30(3): 213-241.

Creed, W.E.D., Scully, M.A., \& Austin, J.R. Clothes make the person? The tailoring of legitimating accounts and the social construction of identity. Organization Science, 13(5):475-496.

Creed, W.E.D., DeJordy, R., \& Lok, J. (2010) Being the change: Resolving institutional contradiction through identity work. Academy of Management Journal, $53,1336-1364$.

Cunliffe, A. (2002) Reflexive dialogical practice in management learning. Management Learning, 33(1): 35-61. 
Daniels, K. (2006) Rethinking job characteristics in work stress research. Human Relations, 59(3): 267-290.

Diedrich, A. and Guzman, G. (2015) From implementation to appropriation: understanding knowledge management system development and introduction as a process of translation, Journal of Knowledge Management, 19(6): 1273-1294.

Dornan, T., Pearson, E., Carson, P., Helmich, E. and Bundy, C. (2015) Emotions and identity in the figured world of becoming a doctor, Medical Education, 49: 174-185.

Ekman, P., \& Friesen, W. V. (1969). The repertoire of nonverbal behavior: Categories, origins, usage, and coding. Semiotica, 1, 49-98.

Engestrom, Y. (1999) Expansive visibilization of work: An activity-theoretical perspective. Journal of Collaborative Computing, 8(1): 63-93.

Erickson, F. (2011) Uses of video in social research: a brief history. International Journal of Social Research Methodology, 14(3): 179-189.

Eatough, E.M., Meier, L.L., Igic, I., Elfering, A., Spector, P.E. and Semmer, N, K. (2016) You want me to do what? Two daily diary studies of illegitimate tasks and employee well-being, Journal of Organizational Behavior, 37: 108-127.

Ernst, W. (2013) Digital Memory and the Archive. Minneapolis. University of Minnesota.

Gibson, B.E. (2005) Co-producing video diaries: The presence of the 'absent' researcher. International Journal of Qualitative Methods, 4(4): 1-10.

Ginsburg, F. (1991) Indigenous media: Faustian contract or global village? Cultural Anthropology, 6(1): 92-112. 
Green, W. and Cluley, R. (2014) The field of radical innovation: making sense of organizational cultures and radical innovation, Industrial Marketing Management, 43: 1343-1350.

Gubrium, A.C., Hill, A.L, \& Flicker, S. (2014) A situated practice of ethics for participatory visual and digital methods in public health research and practice: A focus on digital storytelling. American Journal of Public Health, 104(9): 1606-1626.

Gylfe, P. Frank, H. LeBaron, C. \& Mantere, S. (2016) Video methods in strategy research: focusing on embodied cognition. Strategic Management Journal, 37: 133148.

Hancock, P. (2008) Embodied generosity and an ethics of organization. Organization Studies, 29(10): 1357-1373.

Harries-Jones, P. (1995). A recursive vision: Ecological understanding and Gregory Bateson. London: University of Toronto Press.

Hassard, J., Holliday, R., Willmott, H. (2000) Body and organization. London, Sage.

Hindmarsh, J. \& and Pilnick, A. (2007) Knowing bodies at work: Embodiment and ephemeral teamwork in anaesthesia. Organization Studies, 28(9): 1395-1416.

Hindmarsh, J. \& Heath, C. (2011) Video-based studies of work practice. Sociology Compass, 1(1): 156-173.

Holliday, R. (2000) We've been framed: visualizing methodologies. The Sociological Review, 48(4): 503-522.

Iedema, R., Forsyth, R., Georgiou, A., Braithwatie, J. \& Westbrook, J. (2006) Video research in health. Qualitative Research Journal 6(2): 15-30. 
Jarventie-Theseff, R. \& Tienari, J. (2016) Roles as mediators in identity work. Organization Studies, 37(2): 237-265.

Jarzabkowski, P., Burke, G. \& Spee, P. (2015) Constructing spaces for strategic work: a multimodal perspective. British Journal of Management, 26:26-47.

Kittler, F. (1986) Grammophon, Film, Typewriter. Transl. G. Winthrop-Young \& M. Wutz. Stanford. Stanford University Press.

Knoblauch, H. \& Schnettler, B. (2012) Videograpy: Analyzing video data as 'focused' ethnographic and hermeneutical exercise. Qualitative Research 12(3): 334356.

Knorr-Cetina, K. (1991) Epistemic cultures: Forms of reason in science. History of Political Economy, 23(1): 105-123.

Langley, A., Smallman, C., Tsoukas, H. \& Van de Ven, A. Process studies of change in organization and management: Unveiling temporality, activity, and flow. Academy of Management Journal, 56(1): 1-13.

Lausberg, H. and Sloejes, H. (2009) Coding gestural behavior with the NUEROGESELAN system, Behavioral Research Methods, 41(3), 841-849.

LeBaron, C., \& Jones, S. (2002). Closing up closings: Showing the relevance of the social and material surround to the completion of an interaction. Journal of Communication, 52(3): 542: 566.

LeBaron, C.; Glenn, P. \& Thopmson, M.P. (2009) in: Exploring positive identities and organizations, ed. L. Morgan Roberts \& J.E. Dutton. London: Routledge: 191214. 
Lehtinen, E. \& Palli, P. (2011) Conversational use of genres in managerial meetings. Scandinavian Journal of Management, 21: 287-296.

Lemke, J. (2007), “Video epistemology in- and outside the box: traversing attentional spaces”,

in Goldman, R., Pea, R., Barron, B. and Derry, S. (Eds), Video Research in the Learning

Sciences, Lawrence Erlbaum Associates, Mahwah, NJ, pp. 39-51.

Leung, A., Zietsma,C. \& Peredo, A.M. (2014) Emergent identity and institutional change: the 'quiet' revolution of Japanese middle-class housewives. Organization Studies, 35(3): 423-450.

Lewellyn, N. (2011) The gift in interaction: a study of 'picking up the bill'. The British Journal of Sociology, 62(4): 718-739.

Liu, F. \& Maitlis, S. (2014) Emotional dynamics and strategizing processes: a study of strategic conversations in top team meetings. Journal of Management Studies, 51 (2), pp. 202-234

Lorino, P., Tricard, B. \& Clot, Y. (2011) Research methods for non-representational approaches to organizational complexity: the dialogical mediated inquiry. Organization Studies, 32(6): 769-801.

MacDougall, D. (1997). 'The visual in anthropology'. In Banks, M. and Morhpy, H. (Eds), Rethinking Visual Anthropology. London: New Haven Press, 276-95.

MacIntosh, R. \& McLean, D. (2015) Strategic management: Strategists at work. Plagrave: London.

McColl-Kennedy, J.R., Cheung, L. and Ferrier, E. (2015) Co-creating service experience practices, Journal of Services Marketing, 26(2): 249-275.

Manusov, V. \& Trees, A.R. (202) Are you kidding me? : the role of nonverbal cues in the verbal accounting process. Journal of Communication, 52(3): 640-656. 
Marsh, K. \& Musson, G. (2008) Men at home and at work: managing emotion in telework. Gender, Work \& Organization15(1): 31-50.

Mason, K. (2010) Market sensing and situated dialogic action research (with a video camera). Management Learning, 43(4): 405-425.

Mattarelli, E., Bertolotti, F. and Incerti, V. (2015) The interplay between organizational polychronicity, multitasking behaviors and organizational identification: a mixed methods study in knowledge intensive organizations, International Journal of Human-Computer Studies, 79: 6-19.

Meyer, R., Hollerer, M.A., Jancsary, D. \& van Leeuwen, T. (2013) The visual dimension in organizing, organization, and organization research. The Academy of Management Annals, 7(1): 487-553.

McLuhan, M. (1964/2001) Understanding Media. London: Routledge.

Mondada, L. (2006) Video recording as the reflexive preservation and configuration of ophenomenal features for analysis. In: Video Analysis, H. Knoblauch, H. Raab, J. Soeffner, H-G., \& Schnettler, B. (eds). Bern: Lang, pp. 1-18.

Muir, S. \& Mason, J. (2012) Capturing Christmas: The sensory potential of data from participant produced video. Sociological Research Online, 17(1).

Mumford, C., (2016) Video 'talks back' in a relational research approach. Qualitative Research in Organizations and Management. An International Journal, 11(2): 92-109. Pauwels, L. (2010) Visual sociology reframed: An analytical synthesis and discussion of visual methods in social and cultural research. Sociological Methods and Research, 38(4): 545-581. 
Pilbeam, C., Davidson, R., Doherty, N. and Denyer, D. (2016) What learning happens? Using audio diaries to capture learning in response to safety-related events within retail and logistics organizations, Safety Science, 81: 59-67.

Pinchevsky, A. (2012) The Audiovisual Unconscious: Media and Trauma in the Video Archive for Holocaust Testimonies. Critical Inquiry, 39: 141-166.

Plowman, P.J. (2010) The diary project: Revealing the gendered organisation. Qualitative Research in Organisations and Management: An International Journal, $5(1), 28-46$

Prins, S. (2002). 'Guidelines for the evaluation of ethnographic visual media: historical background'. American Anthropologist, 104, 303-5.

Radclliffe, L. (2013) Qualitative diaries: uncovering the complexities of work-life decision-making. Qualitative Research in Organizations and Management. 8(2): 163180.

Radcliffe, L. (2016) Using qualitative diaries to uncover the complexities of daily experiences. In K. Townsend, R. Loudoun and D. Lewin (Eds) Handbook of Qualitative Research Methods in HRM: Innovative Techniques. Cheltenham: Edward Elgar

Riach, K. \& Warren, S. (2015) Smell organizations: Bodies and corporeal porosity in office work. Human Relations, 68(5): 89-809.

Samra-Fredericks, D. (2010) Ethnomethodology and the moral accountability of interaction: Navigating the conceptual terrain of 'face' and face-work. Journal of Pragmatics, 42: 2147-2157. 
Smets, M., Burke, G., Jarzabkowski, P. \& Spee, P. (2014) Charting new territory for organizational ethnography: Insights from a team-based video ethnography. Journal of Organizational Ethnography, 3(1): 10-26.

Spender, J.C. (1989) Industry recipes: the nature and sources of managerial judgment. Oxford: Blackwell.

Strati, A., (2007) Sensible knowledge and practice-based learning. Management Learning, 38(1): 61-77.

Suchman. L. (1995) Making work visible. Communication of the ACM. Vol. 38(9): $56-64$.

Suchman, L. (2000) Embodied practices of engingeering work. Mind, Culture, and Actiity. 7(1): 4-18.

Turner, T. (1992) Defiant Images: The Kayapo appropriation of video. Anthropology Today, 8(6): 5-16.

Uy, M. A., Foo, M.-D. \& Aguinis, H. (2010) Using experience sampling methodology to advance entrepreneurship theory and practice. Organizational Research Methods, $13(1) 31-54$.

Warren, S. (2008) Empirical challenges in in organizational aesthetics research: towards a sensual methodology. Organization Studies, 29(4):559-580.

Williams, R. (2004) Television. Technology and cultural form. Ed. E Williams. London: Routledge. 
